Article

\title{
Degeneration of Aortic Valves in a Bioreactor System with Pulsatile Flow
}

\author{
Naima Niazy ${ }^{1}$, Mareike Barth ${ }^{1}$, Jessica I. Selig ${ }^{1}$, Sabine Feichtner ${ }^{1}{ }^{\mathbb{D}}$, Babak Shakiba $^{1}$, Asya Candan ${ }^{1}$, \\ Alexander Albert ${ }^{1,2}$, Karlheinz Preuß ${ }^{3}$, Artur Lichtenberg ${ }^{1, *}$ and Payam Akhyari ${ }^{1}$ (D)
}

1 Department of Cardiac Surgery, Medical Faculty, University Hospital Düsseldorf, Heinrich-Heine-University Düsseldorf, Moorenstraße 5, 40225 Düsseldorf, Germany; niazy.naima@gmail.com (N.N.); mareike.barth@med.uni-duesseldorf.de (M.B.); jessica.selig@med.uni-duesseldorf.de (J.I.S.); sabine.feichtner@hotmail.de (S.F.); babak.shakiba@hhu.de (B.S.); asya.candan@hhu.de (A.C.); Alexander.Albert@klinikumdo.de (A.A.); payam.akhyari@med.uni-duesseldorf.de (P.A.)

2 Department of Cardiovascular Surgery, Klinikum Dortmund gGmbH, Beurhausstraße 40, 44137 Dortmund, Germany

3 Faculty of Biotechnology, Bioprocessing, Modulation and Simulation, University of Applied Sciences Mannheim, Paul-Wittsack-Straße 10, 68163 Mannheim, Germany; k.preuss@hs-mannheim.de

* Correspondence: Artur.Lichtenberg@med.uni-duesseldorf.de

Citation: Niazy, N.; Barth, M.; Selig, J.I.; Feichtner, S.; Shakiba, B.; Candan, A.; Albert, A.; Preuß, K.; Lichtenberg, A.; Akhyari, P. Degeneration of Aortic Valves in a Bioreactor System with Pulsatile Flow. Biomedicines 2021, 9, 462. https://doi.org/10.3390/ biomedicines 9050462

Academic Editor: María García-Díaz

Received: 31 March 2021

Accepted: 21 April 2021

Published: 23 April 2021

Publisher's Note: MDPI stays neutral with regard to jurisdictional claims in published maps and institutional affiliations.

Copyright: (c) 2021 by the authors. Licensee MDPI, Basel, Switzerland. This article is an open access article distributed under the terms and conditions of the Creative Commons Attribution (CC BY) license (https:/ / creativecommons.org/licenses/by/ $4.0 /)$.

\begin{abstract}
Calcific aortic valve disease is the most common valvular heart disease in industrialized countries. Pulsatile pressure, sheer and bending stress promote initiation and progression of aortic valve degeneration. The aim of this work is to establish an ex vivo model to study the therein involved processes. Ovine aortic roots bearing aortic valve leaflets were cultivated in an elaborated bioreactor system with pulsatile flow, physiological temperature, and controlled pressure and $\mathrm{pH}$ values. Standard and pro-degenerative treatment were studied regarding the impact on morphology, calcification, and gene expression. In particular, differentiation, matrix remodeling, and degeneration were also compared to a static cultivation model. Bioreactor cultivation led to shrinking and thickening of the valve leaflets compared to native leaflets while gross morphology and the presence of valvular interstitial cells were preserved. Degenerative conditions induced considerable leaflet calcification. In comparison to static cultivation, collagen gene expression was stable under bioreactor cultivation, whereas expression of hypoxia-related markers was increased. Osteopontin gene expression was differentially altered compared to protein expression, indicating an enhanced protein turnover. The present ex vivo model is an adequate and effective system to analyze aortic valve degeneration under controlled physiological conditions without the need of additional growth factors.
\end{abstract}

Keywords: calcific aortic valve disease; degeneration; bioreactor system; tissue cultivation; ECM remodeling

\section{Introduction}

Calcific aortic valve disease (CAVD) is the most common valvular heart disease in developed countries. CAVD is characterized by thickening of the valve leaflets and subsequent tissue calcification resulting in functional aortic stenosis leading to heart failure and death if not treated. Other factors contributing to CAVD development are well defined cardiovascular risk factors, e.g., hypertension, smoking, obesity, and diabetes [1]. Presently, surgical or trans-catheter valve replacement is the only established treatment [2]. On the mechanistic level, CAVD is an active biological process characterized by leaflet stiffening, formation of extracellular calcified nodules [3], altered extracellular matrix (ECM) turnover [4], and phenotype changes in valvular interstitial cells (VIC) [5-7]. Under physiologic conditions in vivo, the aortic valve is exposed to a complex environment of cyclic tensile, shear and flexural stress inducing strain in circumferential and radial direction. Due to its anatomical position it is exposed to higher pressure and shear stress values than other heart valves [8]. VIC proliferation, collagen synthesis, and calcification are 
known to be affected by strain state and flexural deformation of the leaflet [9-11]. Ex vivo models showed that flow alone can promote differentiation of fibroblasts into activated myofibroblasts [10], and stretching of valves results in calcification and expression of pro-degenerative markers [12]. Aortic valve regurgitation likewise results in changes in gene expression common to those occurring in CAVD progression [13]. Moreover, abnormal fluid sheer stress frequencies induce the expression of pro-degenerative markers and enhance the expression of matrix metalloproteinase 2 and 9 (MMP2 and MMP9) and their activity [14]. However, under experimental settings biaxial stretching may result in preservation of native micro ECM structure [15]. Examinations of individual leaflets or parts thereof make up the majority of settings in previous studies. However, these settings do not fully represent the conditions of valve deformation during physiologic cyclic loading $[8,12,15,16]$. Therefore, alternative model systems are required that reflect physiological conditions during circular opening and closing due to pulsatile flow through the valve. Nevertheless, bioreactors allowing pulsatile flow through an intact aortic valve are mainly known in the context of tissue engineering and therefore used in experiments involving tissue engineered bioprosthetic devices or decellularized conduits $[17,18]$. Hence in the presented work, a computer-controlled bioreactor system is presented that allows cultivation of valve bearing native aortic roots under controlled physiological conditions and pulsatile flow through the valve as an adequate and effective environment to analyze aortic valve degeneration.

\section{Materials and Methods}

\subsection{Bioreactor Design}

The bioreactor system consists of a tube system and external components for processing of sensor input and regulation of function (Figure 1A). The herein presented bioreactor is an elaborated version of a custom-made prototype bioreactor system that has been previously developed and used for tissue engineering purposes [19]. The bioreactor circuit is composed of a heart valve chamber that harbors the valve bearing native aortic root including the aortic valve. Moreover, the set-up consists of an oxygenation chamber as well as individual sensor probes for online measurement of $\mathrm{pH}$ level (EasyFerm Plus PHI VP120 Pt 100, Hamilton Company, Bonaduz, Switzerland; Stratos E 2402 pH, Knick, Berlin, Germany), $\mathrm{O}_{2}$ saturation (VisiFerm DO 120, Hamilton Company), atmospheric pressure in the oxygenation chamber (Type 8611 eControl, Bürkert Fluid Control Systems, Ingelfingen, Germany) and temperature (Pt100 Class B, custom designed by Engineo, Kelkheim, Germany) (Figure 1B, schematic overview in Figure 1C). According to user determined settings in the process control software values for temperature $\left(37^{\circ} \mathrm{C}\right), \mathrm{pH}$ value $(7.35)$ and chamber pressure ( $107 \mathrm{mbar}$ corresponding to $80 \mathrm{mmHg}$ ) were maintained throughout the cultivation period. Oxygen levels in the circulating medium were recorded and saturation was around $100 \%$. The bioreactor system is entirely controlled by an automated custom designed software system (Engineo). Circulating culture medium was perfused through the heart valve by a pulsatile roller pump (LivaNova, formerly Stöckert, London, $\mathrm{UK}$ ) with 50 rounds per minute (generating a flow of $2.2 \mathrm{~L} / \mathrm{min}$ ) in the herein described experiments. Pressure was regulated through gas flow and $\mathrm{pH}$ level was adjusted by the flexible changing of $\mathrm{CO}_{2}$ supply, again in a fully automated, software-guided pattern. Gas exchange occurred by surface aeration in the oxygenation camber and temperature was regulated by a heating sleeve covering a large part of the perfusion circuit (Figure 1A). 

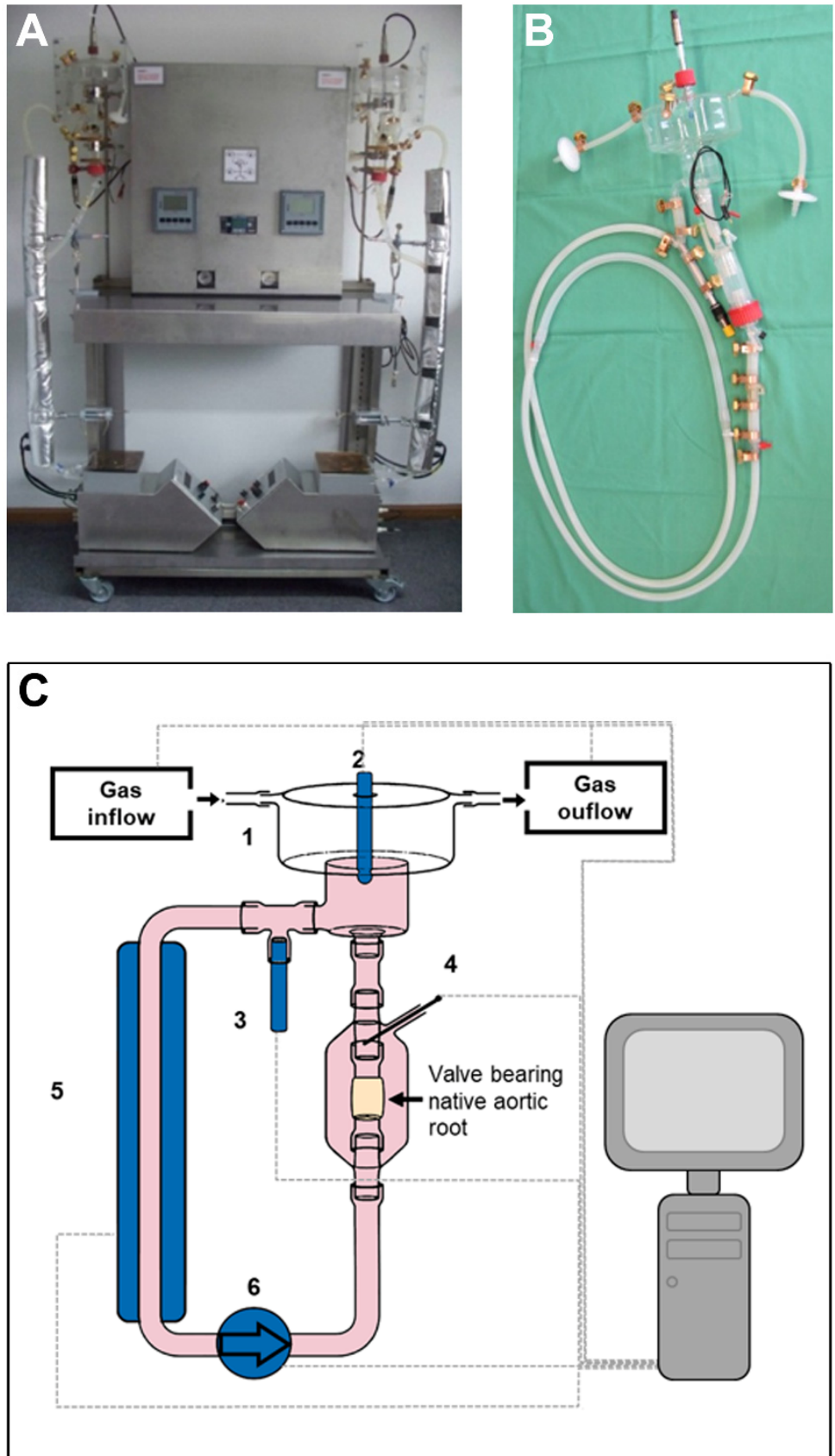

Figure 1. Computer-controlled bioreactor system with pulsatile flow. (A,B) The bioreactor system consists of computer-controlled regulatory elements and a tube system. (C) Schematic overview of the bioreactor system. Gas exchange occurs by surface aeration in the oxygenation camber (1). $\mathrm{pH}$ level (2), oxygen saturation (3), and pressure are measured and maintained via quantity and composition of gas inflow. Temperature (4) is measured and regulated by heating sleeve (5). Perfusion medium is piped through the heart valve by a pulsatile roller pump (6).

\subsection{Cultivation of Valve Bearing Native Aortic Roots}

Valve bearing native aortic roots containing a small rim of adjacent myocardial tissue was dissected from fresh ovine hearts obtained from a local abattoir (Laame, Wuppertal, Germany). Next, valve bearing native aortic roots was washed in PBS with $200 \mathrm{U} / \mathrm{mL}$ penicillin (Thermo Fisher Scientific, Waltham, MA, USA), $200 \mu \mathrm{g} / \mathrm{mL}$ streptomycin (Thermo Fisher Scientific), and $5 \mu \mathrm{g} / \mathrm{mL}$ amphotericin B (Thermo Fisher Scientific) and sewn into the heart valve camber of the bioreactor system under sterile conditions within a conventional flow chamber. The bioreactor circuit (containing oxygen level, $\mathrm{pH}$, and temperature probes) 
was filled with cell culture medium and connected to the bioreactor system. For standard cultivation (BR-std) DMEM with $4.5 \mathrm{mg} / \mathrm{mL}$ glucose and GlutaMAX (Thermo Fisher Scientific) was used containing 10\% fetal calf serum (Sigma-Aldrich, Munich, Germany), non-essential amino acids (Sigma-Aldrich), $200 \mathrm{U} / \mathrm{mL}$ penicillin, $200 \mu \mathrm{g} / \mathrm{mL}$ streptomycin, and $5 \mu \mathrm{g} / \mathrm{mL}$ amphotericin B. For pro-degenerative medium conditions (BR-deg), standard cultivation medium was supplemented with $10 \mathrm{mM} \beta$-glycerophosphate (Sigma-Aldrich) and $1.5 \mathrm{mM}$ calcium chloride (Carl Roth, Karlsruhe, Germany). After seven days of sterile bioreactor cultivation individual aortic valve leaflets were harvested from the aortic root and macroscopic images were taken using a commercial camera (Power Shot SX20IS, Canon, Tokyo, Japan) and a light pad (Slimlite LED 2447, Kaiser, Buchen, Germany). Aortic valve tissue samples were snap frozen in liquid nitrogen immediately at the end of the experiment and stored at $-80^{\circ} \mathrm{C}$ until further use.

For static cultivation valve bearing native aortic roots were dissected, washed, and then cultivated in $50 \mathrm{~mL}$ falcon tubes with loose cap in a cell culture incubator $\left(37^{\circ} \mathrm{C}\right.$, $5 \% \mathrm{CO}_{2} ;$ Heracell $\mathrm{CO}_{2}$ incubator, Thermo Fisher Scientific). Cultivation was performed for seven days with a daily exchange of medium using above-mentioned standard and pro-degenerative conditions (CC-std and CC-deg).

\subsection{Histological Staining and Immunohistochemistry}

Frozen tissue sections of $5 \mu \mathrm{m}$ thickness were fixed with $4 \%$ formalin and subjected to histological and immunohistological staining. Hematoxylin and eosin (H\&E) staining was assessed for orientation and tissue integrity and Movat pentachrome staining was used to assess distribution of collagen, glycosaminoglycans, and elastic fibers within the valvular tissue. Biomineralization was confirmed via Alizarin red and von Kossa staining. Staining procedures were performed as previously described [20,21].

Immunohistological staining was performed as previously described [22] with antibodies targeting vimentin (Progen Biotechnik GmbH, Heidelberg, Germany) and von Willebrand factor (vWF; Agilent Technologies, Santa Clara, CA, USA). Subsequently, sections were stained with alexa488 and alexa594 conjugated secondary antibodies (Thermo Fisher Scientific). Sections were embedded with Vectashield with DAPI (Vector Laboratories, Burlingame, CA, USA). Images of all sections were taken using a Leica DM 2000 and LAS version 3.8 software (Leica Microsystems, Wetzlar, Germany).

\subsection{RNA Isolation and Semi-Quantitative Real-Time PCR ( $q R T-P C R$ )}

Aortic valve leaflets were homogenized and RNA was isolated using trizol chloroform extraction (TRI Reagent, Sigma-Aldrich) according to manufacturer's instructions. Further purification of RNA and reverse transcription were performed using RNeasy Mini Kit (QIAGEN, Hilden, Germany) and QuantiTect Reverse Transcription Kit (QIAGEN) according to manufacturer's specification. RNA integrity (RIN) was measured using Eukaryote Total RNA Nano Chip (Agilent Technologies), whereas all RIN-values were higher than 8.4. Sequence of intron-spanning primers for ribosomal protein L29 (RPL29; reference gene), osteopontin $(O P N)$, collagen type 1 alpha 1 (COL1A1), alkaline phosphatase (ALPL), transforming growth factor beta (TGF $\beta)$, hypoxia-inducible factor 1 alpha $(H I F 1 \alpha)$, and vascular endothelial growth factor (VEGF) are listed in Table 1. Real-time quantitative amplification of RNA was performed using GoTaqR qPCR Master Mix (Promega, Madison, WI, USA) in a StepOnePlus Real Time PCR system according to the manufacturer's instructions (Applied Biosystems Inc., Waltham, MA, USA). Relative gene expression levels were calculated using the delta-delta-CT method. 
Table 1. Primer sequences used for qRT-PCR analysis.

\begin{tabular}{ccc}
\hline Gene of Interest & Forward Primer & Reverse Primer \\
\hline Ribosomal protein L29 $($ RPL29) & CCAAGTCCAAGAACCACACC & TATCGTTGTGATCGGGGTTT \\
Osteopontin $(O P N)$ & GATGGCCGAGGTGATAGTGT & TCGTCTTCTTAGGTGCGTCA \\
Collagen type 1 alpha $1(C O L 1 A 1)$ & AAGACATCCCACCAGTCACC & TAAGTTCGTCGCAGATCACG \\
Alkaline phosphatase $(A L P L)$ & GACATCGCCTACCAGCTCAT & CACATCGGTTCTGTTCTTGG \\
Hypoxia-inducible factor 1 alpha $(H I F 1 \alpha)$ & GAAGCAAAGAATCCATTTTCCA & TGGTGACAACTGATCGAAGG \\
Transforming growth factor beta $(T G F)$ & GAGCCAGAGGCGGACTACTA & TCGGACGTGTTGAAGAACAT \\
Vascular endothelial growth factor $(V E G F)$ & CGGATCAAACCTCACCAAAG & AAATGCTTTCTCCGCTCTGA \\
\hline
\end{tabular}

\subsection{Western Blot Analysis}

For protein isolation, frozen valve tissue samples were mechanically homogenized and sonicated for $10 \mathrm{~min}$ in RIPA buffer (Sigma-Aldrich) containing cOmplete protease inhibitor cocktail (Sigma-Aldrich). Samples were separated on 10\% SDS-PAGE gels and transferred to nitrocellulose membrane (Bio-Rad Laboratories, Munich, Germany) via Western blotting. After blocking for $1 \mathrm{~h}$ with 5\% bovine serum albumin (Sigma-Aldrich) in tris-buffered saline with Tween20 (TBST; 50 mM Tris-Cl [Sigma-Aldrich], $150 \mathrm{mM} \mathrm{NaCl}$ [Merck, Darmstadt, Germany], 0.1\% Tween20 [Merck]), membranes were incubated with primary antibodies specific against alpha smooth muscle actin ( $\alpha$ SMA; Sigma-Aldrich), OPN (Biozol, Eching, Germany) or alpha-tubulin (Sigma-Aldrich). Membranes were washed with TBST and incubated with horseradish peroxidase-conjugated secondary antibodies (Jackson ImmunoResearch, Cambridgeshire, UK; Dianova, Hamburg, Germany) and bands were visualized using WesternBright Chemilumineszenz Substrat Quantum (Advansta, Menlo Park, CA, USA) with an Amersham Imager 600 (GE Healthcare, Chicago, IL, USA).

\subsection{Statistical Analysis}

Data are presented as mean and standard error of mean. Significance was determined with nonparametric testing. Mann-Whitney U test was performed for pairwise comparison of standard and pro-degenerative medium conditions, while Kruskal-Wallis-Test with Dunn's multiple comparisons post-hoc test was used to compare native, BR, and CC culture conditions, respectively. All datasets were analyzed using GraphPad Prism version 5.01 (GraphPad Software, La Jolla, CA, USA). $p$-values $<0.05$ were considered as statistically significant.

\section{Results}

\subsection{Bioreactor Function and Macroscopic Analysis}

The bioreactor system demonstrated continuous and constant operation with maintained physiological parameters throughout each experimental run. At the time of explantation out of the bioreactor chamber, the aortic valve leaflets appeared smaller and thicker for both, BR-std and BR-deg, as compared to native leaflets (Figure 2A, upper panel). Likewise, subsequent lumination through the leaflets showed that leaflets were less translucent after bioreactor cultivation compared to native aortic valve leaflets (Figure 2A, lower panel). Leaflets presented intact structure upon macroscopic examination, with the entire aortic root tissue being free of visible sclerosis after one week of bioreactor-stimulated culture. However, during the experimental cultivation medium color led to slight reddish discoloration after cultivation compared with native control tissue.

On histological level, leaflets displayed intact morphology as determined by H\&E staining (Figure 2B, upper panel). Cell density in the spongiosa varied within biological replicates in all groups ranging from densely populated to a sponge-like appearance with few cells. Other than that, H\&E staining showed a homogeneous cellularity within the leaflet layers. Based on Movat pentachrome staining a three-layered structure of the aortic leaflet tissue was preserved (Figure 2B, lower panel). The aforementioned leaflet thickening 
without major disruption of microarchitecture was observed in all analyzed specimens regardless of the respective medium condition.

A
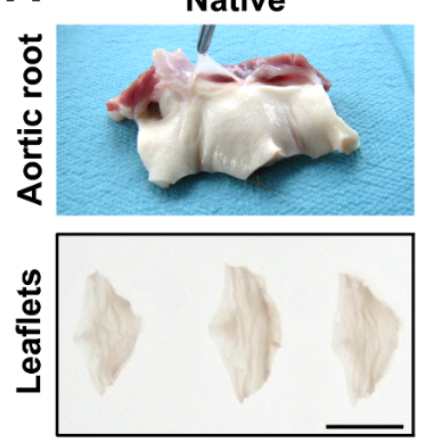

\section{B}
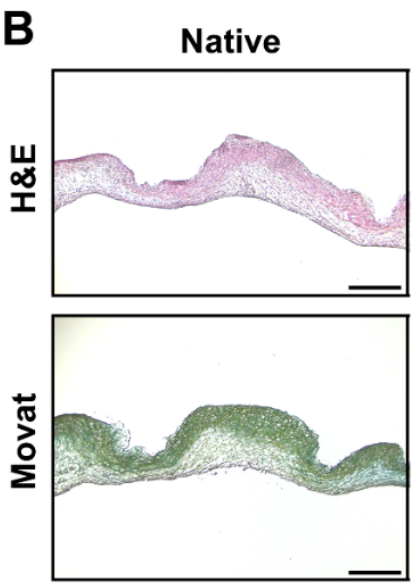

BR-std
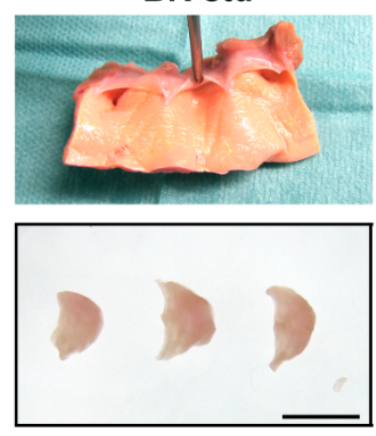

BR-std
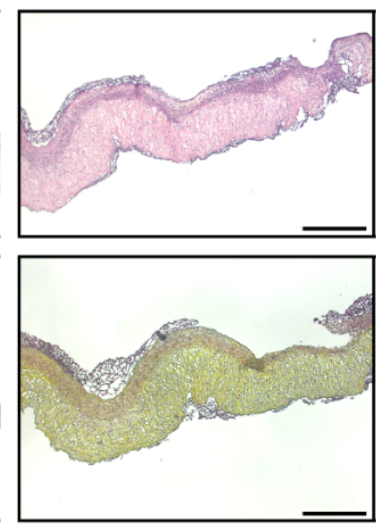

BR-deg
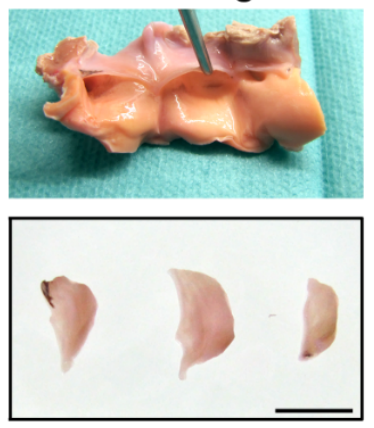

BR-deg
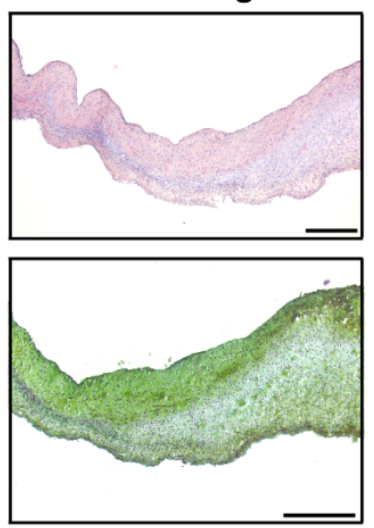

Figure 2. Macroscopic and histological analysis of ovine aortic valve conduits. Valve bearing native aortic roots were cultivated in a bioreactor system with pulsatile flow for one week. (A) Macroscopic analysis after bioreactor cultivation shows no remarkable differences between aortic roots cultivated in standard (BR-std) or pro-degenerative medium containing $\beta$-glycerophosphate and calcium chloride (BR-deg), but a thickening of leaflets compared to native valve bearing aortic roots (Native). Bars: $1 \mathrm{~cm}$. (B) Overall leaflet structure (H\&E staining, upper panel) and three-layer structure of extracellular matrix (Movat pentachrome staining, lower panel) remained after bioreactor cultivation. Representative images of eight replicates are presented. Bars: $400 \mu \mathrm{m}$.

\subsection{Analysis of Tissue Biomineralization and Cell Composition}

In order to assess areas of biomineralization two different histological stainings were applied, Alizarin red and von Kossa staining (Figure 3). In native control and BR-std no biomineralization was detected (Figure 3, left and middle columns). In contrast, under pro-degenerative conditions considerable biomineralization arose in cells of the lamina ventricularis (Figure 3, right column). Small amounts of biomineralization could also be detected in the lamina fibrosa.

In order to characterize the morphology of cells populating the aortic valve tissue after bioreactor cultivation immunohistological staining was applied (Figure 4). Vimentin staining was detected in all layers of native aortic valve leaflets and remained detectable after bioreactor cultivation (Figure 4, left column). In addition, vWF-specific staining was traceable in the endothelial cell layer of native samples lining the aortic valve leaflet on the ventricular and the aortic side (Figure 4, middle column). However, after bioreactor cultivation vWF-specific staining is lost. 

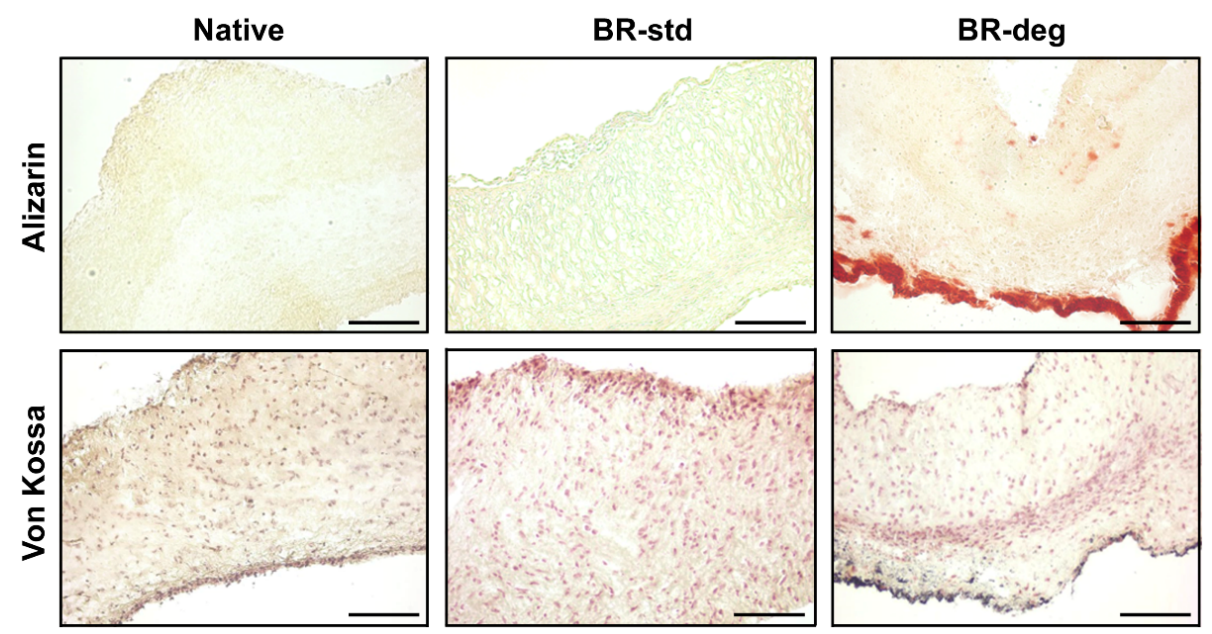

Figure 3. Ex vivo cultivation in pro-degenerative conditions led to biomineralization. Crosssections of native aortic valve leaflets (Native) and leaflets cultivated under standard (BR-std) or pro-degenerative conditions (BR-deg) were stained with Alizarin red (upper panel) and von Kossa (lower panel). Alizarin red staining (red) and von Kossa staining (black) indicating biomineralization, were detected after cultivation in BR-deg, but not in BR-std or native control. Representative pictures of eight replicates were chosen. Bars: $100 \mu \mathrm{m}$.
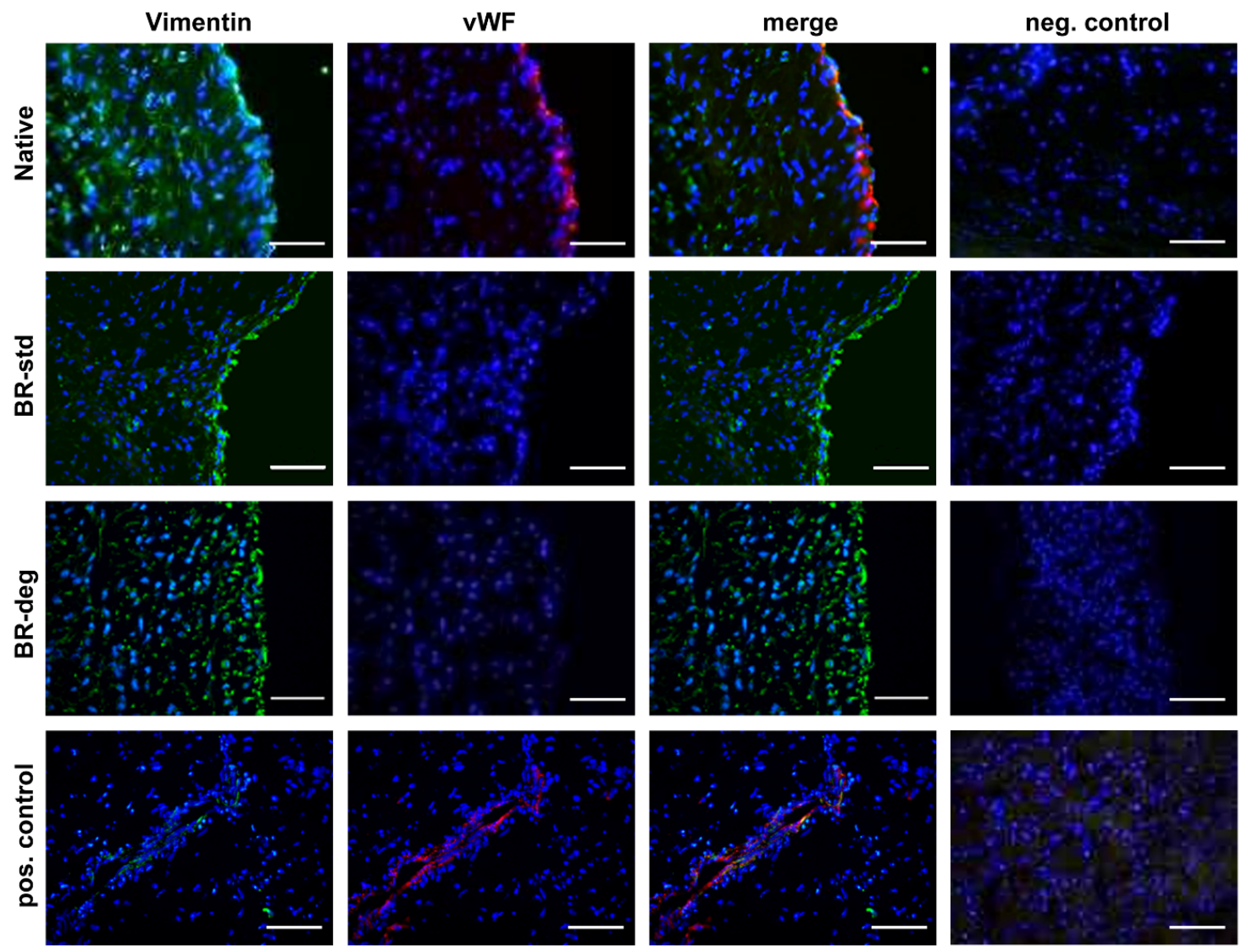

Figure 4. Cellular composition of the aortic valve after bioreactor cultivation. Immune staining with vimentin (green) and vWF (red) specific antibodies was performed on aortic valve cross-sections. Vimentin positive cells were detected in native tissue (first panel) as well as after one week of bioreactor cultivation in standard (BR-std, second panel) pro-degenerative medium (BR-deg, third panel). vWF staining is visible in native aortic valve leaflets (Native, first panel), but not after bioreactor cultivation (second and third panel). Nuclei were counterstained with DAPI. Blood vessels in myocardial specimens served as positive staining control (last panel). Negative control was performed by staining without primary antibodies (right column). Representative pictures of five replicates were chosen. Bars: $50 \mu \mathrm{m}$. 


\subsection{Gene Expression of Pro-Degenerative Markers}

To characterize the effects of bioreactor cultivation with pulsatile medium flow and different medium conditions, gene expression analysis targeting established markers of aortic valve degeneration was performed. The effect of bioreactor cultivation with pulsatile flow was compared to static cultivation and to native aortic valve tissue (Figure 5). Bioreactor cultivation led to a significant increase of $O P N$ expression compared to native aortic valve control (native vs. BR-std: $p=0.0030$; native vs. BR-deg: $p=0.0005$ ) and static cultivation (BR-std vs. CC-std: $p=0.0090$; BR-deg vs. CC-deg: $p=0.0401$ ). However, expression after static cultivation was not significantly altered compared to native control (native vs. CC-std: $p>0.9999$, native vs. CC-deg: $p=0.5727$ ).

In contrast, COL1A1 expression was not altered by bioreactor cultivation compared to native control (native vs. BR-std: $p>0.9999$; native vs. BR-deg: $p>0.9999$ ), but significantly increased compared to static cultivation of the leaflet tissue (BR-std vs. CC-std: $p=0.0014$, BR-deg vs. CC-deg: $p=0.0157)$. COL1A1 expression was also significantly increased under static cultivation compared to native control (native vs. CC-std: $p=0.0030$; native vs. CC-deg: $p=0.0141$ ). Gene expression of $A L P L$ was not significantly altered between culture conditions neither under standard conditions (native vs. BR-std: $p=0.1018$; native vs. CCstd: $p>0.9999 ;$ BR-std vs. CC-std: $p=0.6095$ ) nor under pro-degenerative conditions (native vs. BR-deg: $p=0.0779$; native vs. CC-deg: $p=0.7301$; BR-deg vs. CC-deg: $p=0.8667$ ). However, in degenerative condition a trend toward the downregulation of ALPL in BR-deg compared to native control was observed $(p=0.0779)$.

Moreover, gene expression levels of three key players in neovascularization, namely $T G F \beta, H I F 1 \alpha$, and VEGF, the latter being regulated by HIF1 $\alpha$, were analyzed (Figure 5, lower panel). TGF $\beta$ showed no significant changes neither in bioreactor cultivation (native vs. BR-std: $p>0.9999$; native vs. BR-deg: $p=0.2899$ ) nor in static cultivation compared to native control (native vs. CC-std: $p=0.1211$; native vs. CC-deg: $p>0.9999$ ). Nevertheless, TGF $\beta$ expression was increased under static cultivation compared to bioreactor cultivation (BR-std vs. CC-std: $p=0.0267$; BR-deg vs. CC-deg: $p=0.0296$ ). Likewise, HIF1 $\alpha$ expression was significantly increased after bioreactor cultivation compared to static cultivation (BRstd vs. CC-std: $p=0.0063$; BR-deg vs. CC-deg: $p=0.0005$ ). Furthermore, HIF1 $\alpha$ was by trend downregulated in CC-std when compared to native valve tissue (native vs. CC-std: $p=0.0779$ ). Interestingly, VEGF expression was significantly increased under bioreactor cultivation (native vs. BR-std: $p=0.0090$; native vs. BR-deg: $p=0.0071$ ) as well as under static cultivation (native vs. CC-std: $p=0.0009$; native vs. CC-deg: $p=0.0012$ ) compared to native controls, respectively. A direct comparison of both cultivation systems did not reveal differences in VEGF expression (BR-std vs. CC-std: $p>0.9999$; BR-deg. vs. CC-deg: $p>0.9999$ ).
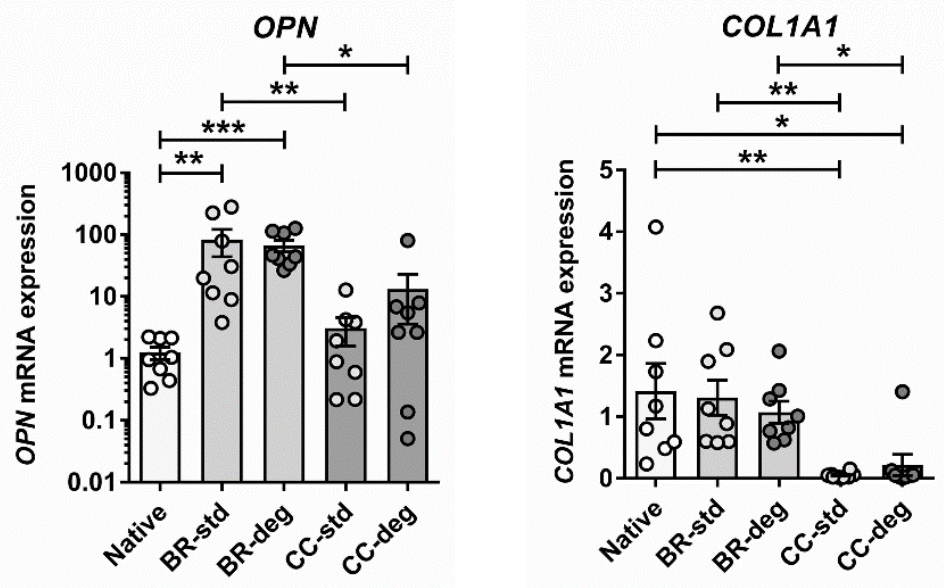

Figure 5. Cont. 
ALPL

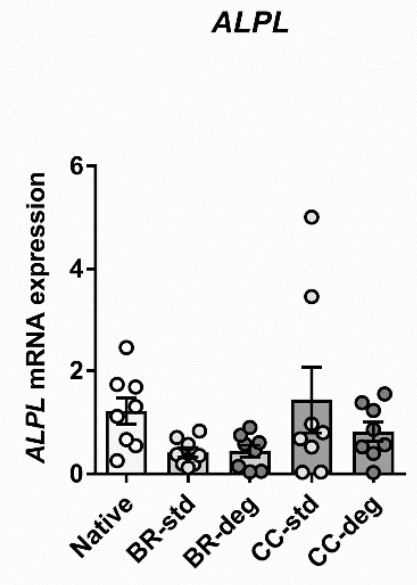

HIF1 $\alpha$

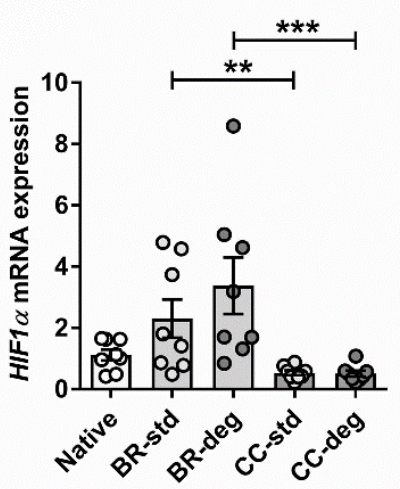

TGF $\beta$
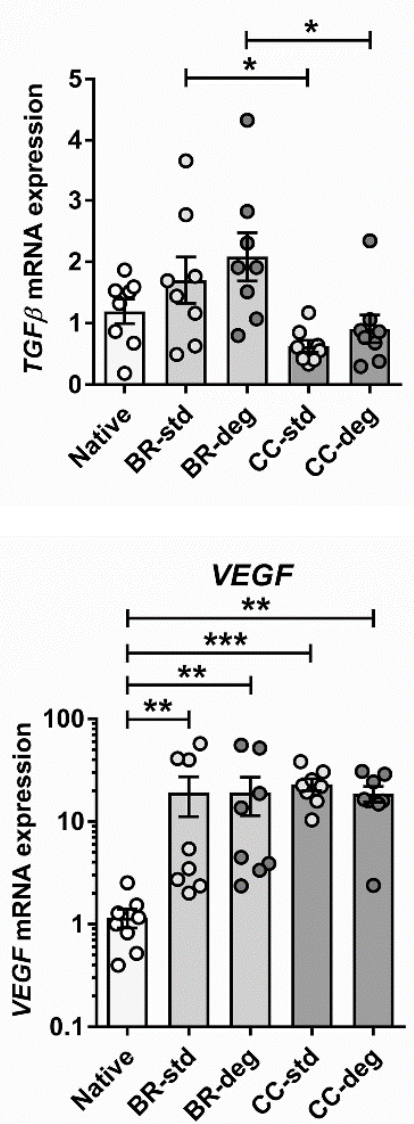

Figure 5. Characterization of the gene expression in aortic valve after bioreactor cultivation compared to static conditions. Valve bearing native aortic roots were cultivated in bioreactor with pulsatile flow (BR) or in a cell culture incubator (CC) for one week using standard medium (BR-std and CC-std) or medium with pro-degenerative conditions (BR-deg and CC-deg). Ovine aortic valve samples were examined using qRT-PCR with specific primers against the housekeeper RLP29, the pro-degenerative markers osteopontin $(O P N)$, collagen type I (COL1A1), alkaline phosphatase (ALPL), and TGF $\beta$ as well as HIF1 $\alpha$ and VEGF. Values are shown as means and standard error of means, dots indicate eight biological replicates. For statistical analysis Mann-Whitney test was performed to compare standard and pro-degenerative conditions and Kruskal-Wallis test was used to compare native, BR and CC cultivation. Stars indicate significant differences in Dunn's multiple comparison post-hoc test $\left.{ }^{*} p<0.05 ;{ }^{* *} p<0.01 ;{ }^{* * *} p<0.001\right)$.

\subsection{Bioreactor Mediated Changes on the Protein Level}

To assess the protein level Western blot analysis was performed (Figure 6; for original images of Western blot membranes see Supporting Information). Protein level of $\alpha \mathrm{SMA}$, a marker of VIC differentiation into activated myofibroblast phenotype, was not significantly altered after bioreactor cultivation or static cultivation (Figure 6A,B). Western blot analysis of OPN expression displayed several bands. Expression of $55 \mathrm{kDa}$ OPN was significantly higher in native aortic valves compared to bioreactor cultivation (native vs. BR-std: $p=0.0486$; native vs. BR-deg: $p=0.0327$ ) and static cultivation (native vs. CC-std: $p=0.0112$; native vs. CC-deg: $p=0.0175$ ). In contrast, expression of $32 \mathrm{kDa}$ OPN C-terminal fragment was unaltered. Expression of $15 \mathrm{kDa} C$-terminal OPN was significantly higher in bioreactor cultivation compared to static cultivation under pro-degenerative conditions (BR-deg vs. CC-deg: $p=0.0267$ ) (Figure 6C,D). 
A

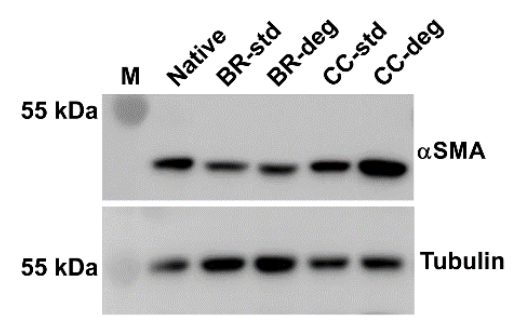

C

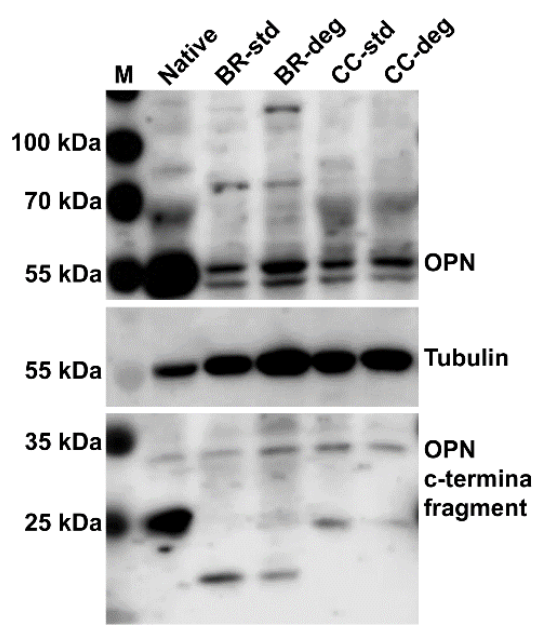

$\alpha$ SMA

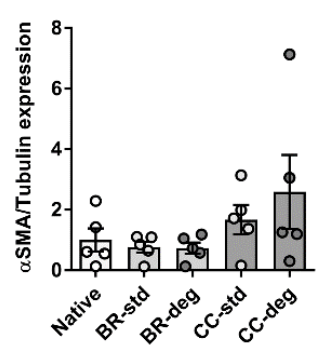

D
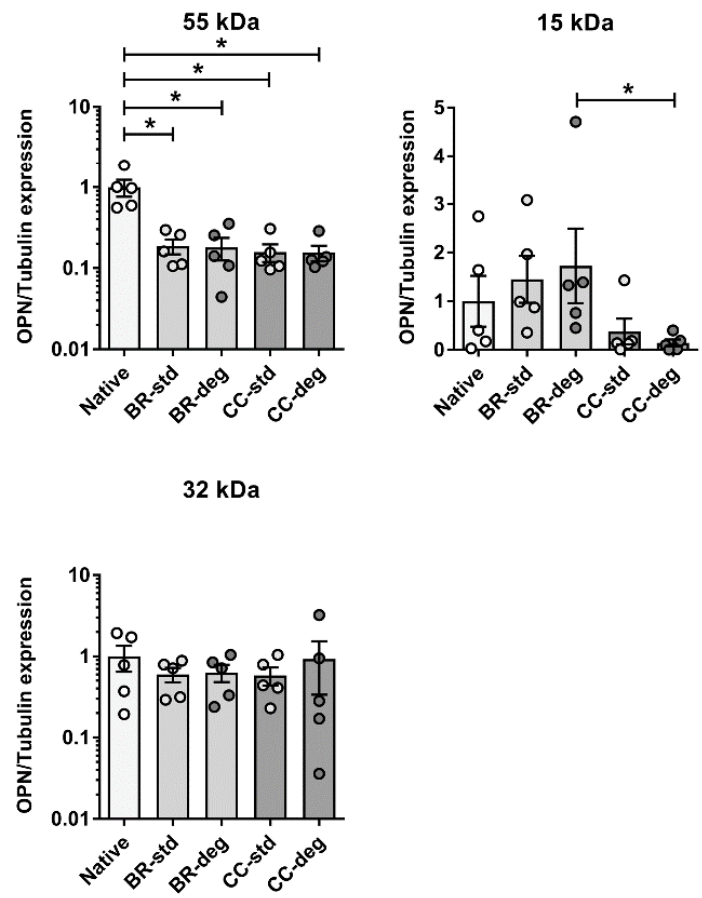

Figure 6. Bioreactor cultivation led to altered OPN protein levels. Lysates were analyzed by Western blot with specific antibodies for (A,B) $\alpha$ SMA, (C,D) osteopontin (OPN), and Tubulin as loading control. Positions of molecular weight markers are indicated on the left. (B,D) Graphic representation of band intensities is displayed on the right, using means and standard error of means $(n=5)$. For OPN protein bands at approximately $55 \mathrm{kDa}$ and $32 \mathrm{kDa}$ were subjected to intensity analysis. Kruskal-Wallis test was performed and significance of Dunn's post-test is indicated with stars $\left({ }^{*} p<0.05\right)$. Control: native leaflets, BR: bioreactor cultivation, CC: static cultivation in cell culture, std: using standard medium, deg: using pro-degenerative medium.

\section{Discussion}

In the present study, we address aortic valve degeneration with a novel ex vivo model. Our data deliver the following insights: (1) The introduced bioreactor system facilitates the induction of biomineralization in aortic valves, without the need of stimulation with pro-degenerative growth factors. (2) Cultivation in pulsatile flow partly prevents altered gene expression due to ex vivo cultivation. (3) OPN expression level and post-translational modification patterns are modified by controlled pulsatile flow.

\subsection{Induction of Biomineralization Due to Bioreactor Cultivation}

The herein presented bioreactor is an effective system to induce biomineralization without a profound manipulation like external TGF $\beta$ treatment. TGF $\beta$ has been previously used to induce calcification in former bioreactor models $[10,23]$ and triggers degenerative 
processes leading to enhanced calcification in CAVD [24,25]. However, TGF $\beta$ also has impact on VIC differentiation, ECM production, and nodule formation [26-29]. Cultivation in the introduced bioreactor system induces biomineralization using pro-degenerative medium without the need of growth factor addition. This process might be triggered by the general loss of the endothelial cell layer during bioreactor cultivation due to the lack of specific endothelial supporting supplements, shown by staining with endothelial cell marker vWF. Loss of endothelial cells as a result of endothelial dysfunction, inflammation, or endothelial-mesenchymal-transition is a hallmark of early aortic valve degeneration [12,30]. Our observation of significantly higher $O P N$ expression under bioreactor cultivation validate this and might favor biomineralization under pro-degenerative medium. Ceasing integrity of the endothelial cell layer triggers VIC activation remodeling and calcium deposition [1]. In bioreactor cultivation, endothelial cell growth may be reduced, since cultivation medium did not contain growth factors commonly used to maintain endothelial cell proliferation. On the other hand, supplements containing growth factors could impact VIC behavior and therefore biomineralization, as mentioned above.

Furthermore, the endothelial cell layer may be disrupted during cultivation after rapid increase of the flow rate in the employed bioreactor system [20]. In our model loss of endothelial cells and biomineralization is visible in both fibrosa and ventricularis, whereas in CAVD valve calcification more frequently occurs on the aortic side of leaflet as opposed to the fibrosa [31-33]. In the fibrosa, the regional wall sheer stress distribution shows more heterogeneity and is more dependent on the valve morphology and the specific phase of the cardiac cycle as compared to the ventricularis layer, making the layer more vulnerable to degeneration $[34,35]$. Even though pulsatile flow during bioreactor cultivation partly mimics native flow patterns, it may not perfectly adapt distribution of wall sheer stress levels that are present in vivo. However, ECM structure remains intact and homogeneous cellularity within the leaflet layers is preserved, indicating sufficient nutrient transport during bioreactor cultivation.

\subsection{Bioreactor Cultivation Leads to Altered Gene Expression Patterns}

Ex vivo cultivation of dissected aortic valve tissue leads to leaflet thickening and significant changes in gene expression, both, in the bioreactor system and during static cultivation in the cell culture incubator. In our bioreactor model, leaflets remain in the native aortic root during cultivation, which allows biomimetic cultivation using pulsatile flow.

However, bioreactor cultivation leads to visible thickening of aortic valve leaflets and increased expression levels of VEGF, which plays a key role in neoangiogenesis. While healthy aortic leaflets are translucent and oxygen supply occurs via diffusion, fibrotic thickening leads to neovascularization during clinically occurring CAVD. This may be due to local hypoxia [36]. Both VEGF and HIF1 $\alpha$ are significantly upregulated in degenerating human aortic valves and expression occurs predominantly in the sites of calcification [37]. Regulation of HIF1 $\alpha$ expression mainly occurs on protein level, where it is rapidly degenerated in normoxic conditions [38,39]. Interestingly, HIF1 $\alpha$ gene expression after bioreactor cultivation is significantly higher than after static cultivation, indicating pulsatile flow may affect HIF1 $\alpha$ expression on RNA level. However, the overall impact may be small since expression compared to native control is not significantly altered in both cultivation conditions.

A similar effect is observed for TGF $\beta$ expression: expression after bioreactor is significantly higher than after static cultivation, but both show no alteration compared to the native control. TGF $\beta$ is known to play a role in neoangiogenesis, but also affects VIC differentiation and ECM turnover [26-29].

Increasing expression of TGF $\beta$ enhances myofibroblast-like activation state of VIC in vitro [40]. Furthermore, mechanical stimuli alone may contribute to transition of VIC from a quiescent phenotype to a myofibroblast phenotype [41-43]. The latter activated myofibroblast-like state of VIC is characterized by elevated $\alpha$ SMA expression [40]. While isolated pathological stretch is known to increase $\alpha \mathrm{SMA}$ expression [44], pressure on aortic 
valve leaflets has been demonstrated to decrease $\alpha \mathrm{SMA}$ expression [45]. A previous study using an ex vivo stretch and pressure bioreactor has observed downregulation of $\alpha \mathrm{SMA}$ protein expression [46]. Our results show no significant changes in $\alpha$ SMA expression after both bioreactor and static cultivation. However, scattering within the biological replicates is wider after static cultivation. Therefore, regulation of $\alpha$ SMA expression may be mechanosensitive, generating a more homogenous expression pattern even though overall expression is not altered. Since expression of $\alpha \mathrm{SMA}$ is unaltered after bioreactor cultivation, an absent impact of bioreactor cultivation on TGF $\beta$ expression matches our other results.

In addition, gene expression levels of $A L P L$ are unaltered after both static and bioreactor cultivation. ALPL is known to promote tissue mineralization via hydrolysis of diphosphate. Nevertheless, ALPL expression was shown to decrease during cultivation of aortic VIC in 2D and 3D [21,47]. Similar effects, though not statistically significant could be observed in our bioreactor model.

On the other hand, COL1A1 expression is preserved in bioreactor cultivation compared to native control but significantly reduced in static cultivation. Collagen is an important component of the ECM that provides structural and functional characteristics to valve tissue including mechanical integrity and biological signaling. Tension, circular, and biaxial stress stimulate collagen expression and increase collagen fiber alignment along the principal directions of strain $[11,44,48]$. Increased collagen expression however remains insignificant depending on the chosen read-out analysis [15]. Therefore, mechanical stimulation is likely to be the cause of preservation of COL1A1 gene expression levels during bioreactor cultivation.

Taken together these results indicate that ex vivo cultivation per se leads to significant changes in gene expression though changes alter between static and bioreactor cultivation.

\subsection{Altered Expression of the Osteogenic Marker OPN}

In our study, we measured OPN gene expression and protein levels of full-length protein as well as C-terminal OPN fragments. Full length OPN is extensively phosphorylated and glycosylated leading to a shift in molecular weight (55-70 kDa) [49]. Phosphorylation of OPN is required for its protective impact on vascular calcification [50,51]. Moreover OPN polymeric complexes formed through crosslinking by transglutaminase 2 are altered in functional properties compared to OPN monomers [52,53]. Intensity of $55 \mathrm{kDa}$ OPN bands shows significantly higher expression in native aortic leaflets compared to bioreactor or static cultivation, indicating higher expression of full length OPN in native leaflets. On the other hand OPN is cleaved by several matrix metalloproteases and thrombin into a $\mathrm{N}$-terminal and an integrin binding C-terminal fragment [54,55]. In our setting the amount of detected C-terminal OPN fragment (approx. $32 \mathrm{kDa}$ ) is not significantly altered between native, bioreactor, and static condition. However, the amount of $15 \mathrm{kDa}$ fragment, a further cleaved fragment of C-terminal OPN, is increased after bioreactor cultivation and significantly higher in BR-deg compared to CC-deg. In standard condition, differences remain insignificant due to high standard deviation within the groups. OPN gene expression is highly elevated in BR conditions compared to native valve, while protein levels are reduced for full-length protein and constant or increased, respectively, for degradation products. Overall, this result might hint at an altered turnover of OPN due to bioreactor cultivation.

A recent study comparing calcified and non-calcified human aortic valves observed elevated OPN RNA levels and elevated OPN plasma levels while OPN protein expression within the leaflet was significantly reduced in calcified valves of the examined patient group [56].

It is known that OPN intensively stains calcified regions in sclerotic aortic valves $[57,58]$ but the functional role of OPN in CAVD is still controversial. OPN may bind to apatite crystals and is considered as a potential mineralization inhibitor [59] though at the same time OPN expression increases with the progression and calcification in human aortic valve tissue [60] suggesting a pro-degenerative role. Splice variants and post-translational 
modification may affect the role of OPN within disease progression [51,58]. Therefore, further analysis should aim to identify modality of OPN posttranslational modification and verify altered cleavage patterns due to cultivation in pulsatile flow.

\section{Conclusions}

In this study, we present a novel ex vivo model to analyze aortic valve degeneration under controlled physiological conditions and pulsatile flow while retaining ECM structure. Bioreactor cultivation under pro-degenerative conditions leads to considerable biomineralization within the valve tissue without requiring additional stimulation by $\mathrm{cy}-$ tokines or growth factors. Moreover, cultivation in pulsatile flow in part preserves COL1A1 expression and modulates the expression of genes involved in response of hypoxia and also tissue protein expression of OPN. In conclusion, the established ex vivo model is an effective system to analyze aortic valve degeneration under controlled physiological conditions while retaining the morphological integrity.

Author Contributions: Conceptualization, N.N. and P.A.; methodology, N.N. and P.A.; software, K.P.; validation, N.N. and P.A. and A.L.; formal analysis, N.N.; investigation, N.N., S.F., B.S. and A.C.; resources, A.L.; data curation, N.N. and P.A.; writing—original draft preparation, N.N., M.B., J.I.S. and P.A.; writing—review and editing, M.B., J.I.S., A.A., A.L. and P.A.; visualization, N.N., M.B.; supervision, N.N., A.L. and P.A.; project administration, P.A. All authors have read and agreed to the published version of the manuscript.

Funding: This research received no external funding.

Institutional Review Board Statement: Not applicable.

Informed Consent Statement: Not applicable, since ovine cardiac tissue was obtained from the slaughterhouse and was approved for consumption.

Data Availability Statement: The data presented in this study are available on reasonable request from the corresponding author.

Acknowledgments: The authors thank Gisela Müller (Department of Cardiac Surgery, University Hospital Düsseldorf, Heinrich-Heine-University Düsseldorf) and Detlev Rohrbach (Department of Pharmacology and Clinical Pharmacology, Heinrich-Heine-University Düsseldorf) for technical support. The generous support of the S. Bunnenberg Foundation to the Cardiovascular Research Facilities at the Heinrich Heine University Düsseldorf is greatly appreciated. This research did not receive any specific grant from funding agencies in the public, commercial, or not-for-profit sectors.

Conflicts of Interest: The authors declare no conflict of interest.

\section{References}

1. Lindman, B.R.; Clavel, M.-A.; Mathieu, P.; Iung, B.; Lancellotti, P.; Otto, C.M.; Pibarot, P. Calcific aortic stenosis. Nat. Rev. Dis. Primers 2016, 2, 16006. [CrossRef]

2. Beckmann, A.; Funkat, A.-K.; Lewandowski, J.; Frie, M.; Ernst, M.; Hekmat, K.; Schiller, W.; Gummert, J.F.; Harringer, W. German Heart Surgery Report 2016: The Annual Updated Registry of the German Society for Thoracic and Cardiovascular Surgery. Thorac. Cardiovasc. Surg. 2017, 65, 505-518. [CrossRef] [PubMed]

3. Freeman, R.V.; Otto, C.M. Spectrum of calcific aortic valve disease: Pathogenesis, disease progression, and treatment strategies. Circulation 2005, 111, 3316-3326. [CrossRef] [PubMed]

4. Latif, N.; Sarathchandra, P.; Taylor, P.M.; Antoniw, J.; Yacoub, M.H. Localization and pattern of expression of extracellular matrix components in human heart valves. J. Heart Valve Dis. 2005, 14, 218-227. [PubMed]

5. Liu, A.C.; Joag, V.R.; Gotlieb, A.I. The emerging role of valve interstitial cell phenotypes in regulating heart valve pathobiology. Am. J. Pathol. 2007, 171, 1407-1418. [CrossRef]

6. Gwanmesia, P.; Ziegler, H.; Eurich, R.; Barth, M.; Kamiya, H.; Karck, M.; Lichtenberg, A.; Akhyari, P. Opposite effects of transforming growth factor-beta1 and vascular endothelial growth factor on the degeneration of aortic valvular interstitial cell are modified by the extracellular matrix protein fibronectin: Implications for heart valve engineering. Tissue Eng. Part A 2010, 16, 3737-3746. [CrossRef]

7. Hortells, L.; Sur, S.; St Hilaire, C. Cell Phenotype Transitions in Cardiovascular Calcification. Front. Cardiovasc. Med. 2018, 5, 27. [CrossRef] 
8. Hasan, A.; Ragaert, K.; Swieszkowski, W.; Selimović, S.; Paul, A.; Camci-Unal, G.; Mofrad, M.R.K.; Khademhosseini, A. Biomechanical properties of native and tissue engineered heart valve constructs. J. Biomech. 2014, 47, 1949-1963. [CrossRef]

9. Wyss, K.; Yip, C.Y.Y.; Mirzaei, Z.; Jin, X.; Chen, J.-H.; Simmons, C.A. The elastic properties of valve interstitial cells undergoing pathological differentiation. J. Biomech. 2012, 45, 882-887. [CrossRef]

10. Fisher, C.I.; Chen, J.; Merryman, W.D. Calcific nodule morphogenesis by heart valve interstitial cells is strain dependent. Biomech Model. Mechanobiol. 2013, 12, 5-17. [CrossRef] [PubMed]

11. Farrar, E.J.; Pramil, V.; Richards, J.M.; Mosher, C.Z.; Butcher, J.T. Valve interstitial cell tensional homeostasis directs calcification and extracellular matrix remodeling processes via RhoA signaling. Biomaterials 2016, 105, 25-37. [CrossRef] [PubMed]

12. Balachandran, K.; Alford, P.W.; Wylie-Sears, J.; Goss, J.A.; Grosberg, A.; Bischoff, J.; Aikawa, E.; Levine, R.A.; Parker, K.K. Cyclic strain induces dual-mode endothelial-mesenchymal transformation of the cardiac valve. Proc. Natl. Acad. Sci. USA 2011, 108, 19943-19948. [CrossRef] [PubMed]

13. Maeda, K.; Ma, X.; Chalajour, F.; Hanley, F.L.; Riemer, R.K. Critical Role of Coaptive Strain in Aortic Valve Leaflet Homeostasis: Use of a Novel Flow Culture Bioreactor to Explore Heart Valve Mechanobiology. J. Am. Heart Assoc. 2016, 5. [CrossRef] [PubMed]

14. Sun, L.; Rajamannan, N.M.; Sucosky, P. Defining the role of fluid shear stress in the expression of early signaling markers for calcific aortic valve disease. PLoS ONE 2013, 8, e84433. [CrossRef] [PubMed]

15. Lei, Y.; Masjedi, S.; Ferdous, Z. A study of extracellular matrix remodeling in aortic heart valves using a novel biaxial stretch bioreactor. J. Mech. Behav. Biomed. Mater. 2017, 75, 351-358. [CrossRef]

16. Weiler, M.; Yap, C.H.; Balachandran, K.; Padala, M.; Yoganathan, A.P. Regional analysis of dynamic deformation characteristics of native aortic valve leaflets. J. Biomech. 2011, 44, 1459-1465. [CrossRef] [PubMed]

17. Amadeo, F.; Boschetti, F.; Polvani, G.; Banfi, C.; Pesce, M.; Santoro, R. Aortic valve cell seeding into decellularized animal pericardium by perfusion-assisted bioreactor. J. Tissue Eng. Regen. Med. 2018, 12, 1481-1493. [CrossRef]

18. Converse, G.L.; Buse, E.E.; Hopkins, R.A. Bioreactors and operating room centric protocols for clinical heart valve tissue engineering. Prog. Pediatric Cardiol. 2013, 35, 95-100. [CrossRef]

19. Lichtenberg, A.; Tudorache, I.; Cebotari, S.; Ringes-Lichtenberg, S.; Sturz, G.; Hoeffler, K.; Hurscheler, C.; Brandes, G.; Hilfiker, A.; Haverich, A. In vitro re-endothelialization of detergent decellularized heart valves under simulated physiological dynamic conditions. Biomaterials 2006, 27, 4221-4229. [CrossRef]

20. Lichtenberg, A.; Cebotari, S.; Tudorache, I.; Sturz, G.; Winterhalter, M.; Hilfiker, A.; Haverich, A. Flow-dependent reendothelialization of tissue-engineered heart valves. J. Heart Valve Dis. 2006, 15, 287-293.

21. Weber, A.; Barth, M.; Selig, J.I.; Raschke, S.; Dakaras, K.; Hof, A.; Hesse, J.; Schrader, J.; Lichtenberg, A.; Akhyari, P. Enzymes of the purinergic signaling system exhibit diverse effects on the degeneration of valvular interstitial cells in a 3-D microenvironment. FASEB J. 2018, 32, 4356-4369. [CrossRef] [PubMed]

22. Assmann, A.; Zwirnmann, K.; Heidelberg, F.; Schiffer, F.; Horstkötter, K.; Munakata, H.; Gremse, F.; Barth, M.; Lichtenberg, A.; Akhyari, P. The degeneration of biological cardiovascular prostheses under pro-calcific metabolic conditions in a small animal model. Biomaterials 2014, 35, 7416-7428. [CrossRef]

23. Balachandran, K.; Sucosky, P.; Jo, H.; Yoganathan, A.P. Elevated cyclic stretch induces aortic valve calcification in a bone morphogenic protein-dependent manner. Am. J. Pathol. 2010, 177, 49-57. [CrossRef]

24. Clark-Greuel, J.N.; Connolly, J.M.; Sorichillo, E.; Narula, N.R.; Rapoport, H.S.; Mohler, E.R., III; Gorman, J.H., III; Gorman, R.C.; Levy, R.J. Transforming growth factor-beta1 mechanisms in aortic valve calcification: Increased alkaline phosphatase and related events. Ann. Thorac. Surg. 2007, 83, 946-953. [CrossRef] [PubMed]

25. Cloyd, K.L.; El-Hamamsy, I.; Boonrungsiman, S.; Hedegaard, M.; Gentleman, E.; Sarathchandra, P.; Colazzo, F.; Gentleman, M.M.; Yacoub, M.H.; Chester, A.H.; et al. Characterization of porcine aortic valvular interstitial cell 'calcified' nodules. PLoS ONE 2012, 7, e48154. [CrossRef] [PubMed]

26. Walker, G.A.; Masters, K.S.; Shah, D.N.; Anseth, K.S.; Leinwand, L.A. Valvular myofibroblast activation by transforming growth factor-beta: Implications for pathological extracellular matrix remodeling in heart valve disease. Circ. Res. 2004, 95, 253-260. [CrossRef]

27. Benton, J.A.; Kern, H.B.; Leinwand, L.A.; Mariner, P.D.; Anseth, K.S. Statins block calcific nodule formation of valvular interstitial cells by inhibiting alpha-smooth muscle actin expression. Arterioscler. Thromb. Vasc. Biol. 2009, 29, 1950-1957. [CrossRef]

28. Jian, B.; Narula, N.; Li, Q.; Mohler, E.R.; Levy, R.J. Progression of aortic valve stenosis: TGF- $\beta 1$ is present in calcified aortic valve cusps and promotes aortic valve interstitial cell calcification via apoptosis. Ann. Thorac. Surg. 2003, 75, 457-465. [CrossRef]

29. Kennedy, J.A.; Hua, X.; Mishra, K.; Murphy, G.A.; Rosenkranz, A.C.; Horowitz, J.D. Inhibition of calcifying nodule formation in cultured porcine aortic valve cells by nitric oxide donors. Eur. J. Pharmacol. 2009, 602, 28-35. [CrossRef]

30. Sucosky, P.; Balachandran, K.; Elhammali, A.; Jo, H.; Yoganathan, A.P. Altered shear stress stimulates upregulation of endothelial VCAM-1 and ICAM-1 in a BMP-4- and TGF-beta1-dependent pathway. Arterioscler. Thromb. Vasc. Biol. 2009, 29, 254-260. [CrossRef]

31. Sewell-Loftin, M.-K.; Brown, C.B.; Baldwin, H.S.; Merryman, W.D. A novel technique for quantifying mouse heart valve leaflet stiffness with atomic force microscopy. J. Heart Valve Dis. 2012, 21, 513-520. [PubMed]

32. Merryman, W.D.; Huang, H.-Y.S.; Schoen, F.J.; Sacks, M.S. The effects of cellular contraction on aortic valve leaflet flexural stiffness. J. Biomech. 2006, 39, 88-96. [CrossRef] [PubMed] 
33. Haskett, D.; Johnson, G.; Zhou, A.; Utzinger, U.; Vande Geest, J. Microstructural and biomechanical alterations of the human aorta as a function of age and location. Biomech. Model. Mechanobiol. 2010, 9, 725-736. [CrossRef] [PubMed]

34. Cao, K.; Sucosky, P. Computational comparison of regional stress and deformation characteristics in tricuspid and bicuspid aortic valve leaflets. Int. J. Numer. Method Biomed. Eng. 2017, 33. [CrossRef]

35. Otto, C.M.; Kuusisto, J.; Reichenbach, D.D.; Gown, A.M.; O'Brien, K.D. Characterization of the early lesion of 'degenerative' valvular aortic stenosis. Histological and immunohistochemical studies. Circulation 1994, 90, 844-853. [CrossRef]

36. Sapp, M.C.; Krishnamurthy, V.K.; Puperi, D.S.; Bhatnagar, S.; Fatora, G.; Mutyala, N.; Grande-Allen, K.J. Differential cell-matrix responses in hypoxia-stimulated aortic versus mitral valves. J. R. Soc. Interface 2016, 13. [CrossRef]

37. Perrotta, I.; Moraca, F.M.; Sciangula, A.; Aquila, S.; Mazzulla, S. HIF-1alpha and VEGF: Immunohistochemical Profile and Possible Function in Human Aortic Valve Stenosis. Ultrastruct. Pathol. 2015, 39, 198-206. [CrossRef] [PubMed]

38. Lim, C.S.; Kiriakidis, S.; Sandison, A.; Paleolog, E.M.; Davies, A.H. Hypoxia-inducible factor pathway and diseases of the vascular wall. J. Vasc. Surg. 2013, 58, 219-230. [CrossRef]

39. Masson, N.; Willam, C.; Maxwell, P.H.; Pugh, C.W.; Ratcliffe, P.J. Independent function of two destruction domains in hypoxiainducible factor-alpha chains activated by prolyl hydroxylation. EMBO J. 2001, 20, 5197-5206. [CrossRef]

40. Liu, A.C.; Gotlieb, A.I. Transforming growth factor-beta regulates in vitro heart valve repair by activated valve interstitial cells. Am. J. Pathol. 2008, 173, 1275-1285. [CrossRef]

41. Rajamannan, N.M.; Subramaniam, M.; Rickard, D.; Stock, S.R.; Donovan, J.; Springett, M.; Orszulak, T.; Fullerton, D.A.; Tajik, A.J.; Bonow, R.O.; et al. Human aortic valve calcification is associated with an osteoblast phenotype. Circulation 2003, 107, 2181-2184. [CrossRef] [PubMed]

42. Rutkovskiy, A.; Malashicheva, A.; Sullivan, G.; Bogdanova, M.; Kostareva, A.; Stenslokken, K.-O.; Fiane, A.; Vaage, J. Valve Interstitial Cells: The Key to Understanding the Pathophysiology of Heart Valve Calcification. J. Am. Heart Assoc. $2017,6$. [CrossRef] [PubMed]

43. Rattazzi, M.; Iop, L.; Faggin, E.; Bertacco, E.; Zoppellaro, G.; Baesso, I.; Puato, M.; Torregrossa, G.; Fadini, G.P.; Agostini, C.; et al. Clones of interstitial cells from bovine aortic valve exhibit different calcifying potential when exposed to endotoxin and phosphate. Arterioscler. Thromb. Vasc. Biol. 2008, 28, 2165-2172. [CrossRef]

44. Balachandran, K.; Konduri, S.; Sucosky, P.; Jo, H.; Yoganathan, A.P. An ex vivo study of the biological properties of porcine aortic valves in response to circumferential cyclic stretch. Ann. Biomed. Eng. 2006, 34, 1655-1665. [CrossRef]

45. Xing, Y.; Warnock, J.N.; He, Z.; Hilbert, S.L.; Yoganathan, A.P. Cyclic pressure affects the biological properties of porcine aortic valve leaflets in a magnitude and frequency dependent manner. Ann. Biomed. Eng. 2004, 32, 1461-1470. [CrossRef]

46. Thayer, P.; Balachandran, K.; Rathan, S.; Yap, C.H.; Arjunon, S.; Jo, H.; Yoganathan, A.P. The Effects of Combined Cyclic Stretch and Pressure on the Aortic Valve Interstitial Cell Phenotype. Ann. Biomed. Eng. 2011, 39, 1654-1667. [CrossRef]

47. Orimo, H. The mechanism of mineralization and the role of alkaline phosphatase in health and disease. J. Nippon Med. Sch. 2010, 77, 4-12. [CrossRef]

48. Gould, R.A.; Chin, K.; Santisakultarm, T.P.; Dropkin, A.; Richards, J.M.; Schaffer, C.B.; Butcher, J.T. Cyclic strain anisotropy regulates valvular interstitial cell phenotype and tissue remodeling in three-dimensional culture. Acta Biomater. 2012, 8, 1710-1719. [CrossRef]

49. Christensen, B.; Nielsen, M.S.; Haselmann, K.F.; Petersen, T.E.; Sørensen, E.S. Post-translationally modified residues of native human osteopontin are located in clusters: Identification of 36 phosphorylation and five O-glycosylation sites and their biological implications. Biochem. J. 2005, 390, 285-292. [CrossRef] [PubMed]

50. Sainger, R.; Grau, J.B.; Poggio, P.; Branchetti, E.; Bavaria, J.E.; Gorman, J.H., 3rd; Gorman, R.C.; Ferrari, G. Dephosphorylation of circulating human osteopontin correlates with severe valvular calcification in patients with calcific aortic valve disease. Biomarkers 2012, 17, 111-118. [CrossRef] [PubMed]

51. Jono, S.; Peinado, C.; Giachelli, C.M. Phosphorylation of osteopontin is required for inhibition of vascular smooth muscle cell calcification. J. Biol. Chem. 2000, 275, 20197-20203. [CrossRef]

52. Higashikawa, F.; Eboshida, A.; Yokosaki, Y. Enhanced biological activity of polymeric osteopontin. FEBS Lett. 2007, 581, 2697-2701. [CrossRef]

53. Nishimichi, N.; Hayashita-Kinoh, H.; Chen, C.; Matsuda, H.; Sheppard, D.; Yokosaki, Y. Osteopontin undergoes polymerization in vivo and gains chemotactic activity for neutrophils mediated by integrin alpha9beta1. J. Biol. Chem. 2011, 286, 11170-11178. [CrossRef] [PubMed]

54. Agnihotri, R.; Crawford, H.C.; Haro, H.; Matrisian, L.M.; Havrda, M.C.; Liaw, L. Osteopontin, a novel substrate for matrix metalloproteinase-3 (stromelysin-1) and matrix metalloproteinase-7 (matrilysin). J. Biol. Chem. 2001, 276, 28261-28267. [CrossRef]

55. Kon, S.; Nakayama, Y.; Matsumoto, N.; Ito, K.; Kanayama, M.; Kimura, C.; Kouro, H.; Ashitomi, D.; Matsuda, T.; Uede, T. A novel cryptic binding motif, LRSKSRSFQVSDEQY, in the C-terminal fragment of MMP-3/7-cleaved osteopontin as a novel ligand for $\alpha 9 \beta 1$ integrin is involved in the anti-type II collagen antibody-induced arthritis. PLoS ONE 2014, 9, e116210. [CrossRef]

56. Passmore, M.; Nataatmadja, M.; Fung, Y.L.; Pearse, B.; Gabriel, S.; Tesar, P.; Fraser, J.F. Osteopontin alters endothelial and valvular interstitial cell behaviour in calcific aortic valve stenosis through HMGB1 regulation. Eur. J. Cardiothorac. Surg. 2015, 48, e20-e29. [CrossRef] 
57. Zhiduleva, E.V.; Irtyuga, O.B.; Shishkova, A.A.; Ignat'eva, E.V.; Kostina, A.S.; Levchuk, K.A.; Golovkin, A.S.; Rylov, A.Y.; Kostareva, A.A.; Moiseeva, O.M.; et al. Cellular Mechanisms of Aortic Valve Calcification. Bull. Exp. Biol. Med. 2018, 164, 371-375. [CrossRef] [PubMed]

58. Grau, J.B.; Poggio, P.; Sainger, R.; Vernick, W.J.; Seefried, W.F.; Branchetti, E.; Field, B.C.; Bavaria, J.E.; Acker, M.A.; Ferrari, G. Analysis of osteopontin levels for the identification of asymptomatic patients with calcific aortic valve disease. Ann. Thorac. Surg. 2012, 93, 79-86. [CrossRef] [PubMed]

59. Kahles, F.; Findeisen, H.M.; Bruemmer, D. Osteopontin: A novel regulator at the cross roads of inflammation, obesity and diabetes. Mol. Metab. 2014, 3, 384-393. [CrossRef] [PubMed]

60. Pohjolainen, V.; Taskinen, P.; Soini, Y.; Rysa, J.; Ilves, M.; Juvonen, T.; Ruskoaho, H.; Leskinen, H.; Satta, J. Noncollagenous bone matrix proteins as a part of calcific aortic valve disease regulation. Hum. Pathol. 2008, 39, 1695-1701. [CrossRef] 